\title{
Clostridium difficile-associated diarrhea - The new scourge of the health care facility
}

\author{
JM Conly MD FRCPC
}

C lostridium difficile had its name coined because of the difficulty in its isolation. It was first isolated and described in the mid-1930s and later identified as the etiological agent of pseuodomembranous colitis. The organism, which has been isolated from soil, sand, hay and animal dung, is a Grampositive, spore forming, anaerobic bacillus which produces toxin-mediated diarrhea or pseudomembranous colitis. The organism is now well recognized as the major (if not the only) and most important cause of infectious diarrhea occurring in hospitalized patients in developed countries (1). After colonizing the gastrointestinal tract of humans, the organism causes a wide array of manifestations, ranging from asymptomatic colonization to severe diarrhea, pseudomembranous colitis, toxic megacolon, intestinal perforation and death from secondary sepsis. Two recent publications, one by the Society of Healthcare Epidemiology of America (2) and the other by the American College of Gastroenterology (3), have provided detailed information regarding definitions, diagnosis, management (3) and control strategies for $C$ difficile, and have proven to be useful guidelines for healthcare professionals. However, despite the large amount of data regarding $C$ difficile and its associated diseases, it is troubling that its frequency still continues to increase. It is timely to review new developments in the pathogenesis and epidemiology of $C$ difficile-associated diarrhea (CDAD) and explore the reasons for its apparent increase in the Canadian healthcare setting.

It was previously thought that $C$ difficile was acquired after some period of hospitalization, resulting in asymptomatic colonization by $C$ difficile. The disease developed after antimicrobials were administered that altered the normal colonic flora, allowing the rapid growth of toxin producing strains of $C$ difficile. However, it is now hypothesized that hospitalized patients are intermittently exposed to $C$ difficile throughout their hospitalization but do not acquire $C$ difficile until after receiving antimicrobials; they then develop disease after a brief incubation period (4-6). Recent data from several longitudinal studies suggest that colonized patients are actually at decreased risk for developing symptomatic disease (7). The studies followed 618 noncolonized patients for over $1000 \mathrm{ob}-$ servation weeks and 192 colonized patients for 282 observation weeks. The studies differentiated between those with primary asymptomatic colonization and those who remained culture positive after the resolution of CDAD. It is thought that additional factors related to host immunity or the type and timing of antimicrobial exposure are necessary for $C$ difficile disease to occur. The antibiotics most commonly implicated in $C$ difficile colitis are the third-generation cephalosporin group - ampicillin, amoxicillin and clindamycin. The antimicrobials least likely to be associated with $C$ difficile colitis include parenterally administered aminoglycosides and vancomyin, sulphonamides, and antimicrobial agents that lack antibacterial activity (ie, some antifungal, antiviral and antiparasitic antimicrobials). Among the broad spectrum agents, the third-generation cephalosporins, trovafloxacin (Trovan, Pfizer Canada Inc, Kirkland, Quebec), possibly ciprofloxacin (Cipro, Bayer Healthare Division, Toronto, Ontario) and clindamycin (Dalacin C, Pharmcia \& Upjohn, Mississauga, Ontario) appear to have been implicated most frequently (8-10). For unknown reasons, other broad spectrum agents such as ticarcillin-clavulanate (Timentin, SmithKline Beecham, Oakville, Ontario) and piperacillin-tazobactam (Tazocin, StLaurent, Quebec) have been less frequently implicated. However, virtually all antibiotics have been associated with $C$ difficile colitis. 
$C$ difficile colonization of the colon occurs in approximately $2 \%$ to $3 \%$ of healthy adults. The incidence of communityacquired CDAD (11) is extremely low $(7.7 / 100,000$ person years). The principal reservoirs for $C$ difficile are the hospitalized patient and the hospital environment, with the risk of acquiring the organism increasing in direct proportion to the length of hospital stay. The rate of acquisition has been reported to be $13 \%$ for individuals hospitalized one to two weeks, increasing to as high as $50 \%$ for those hospitalized more than four weeks (12). A recent study conducted through the Canadian Nosocomial Infection Surveillance Program examined the period prevalence, morbidity and health care burden of CDAD in 19 Canadian hospitals and found a prevalence of $5.86 / 1000$ admissions ( $95 \%$ CI 3.4 to 8.4 ) and $66.3 / 100,000$ patient days ( $95 \%$ CI 37.5 to 95.1 ). The vast majority of cases (93\%) developed during the patients' original hospitalization. The overall mortality during the surveillance period of those diagnosed with CDAD was $15.2 \%$, and $9.7 \%$ of the deaths $(1.5 \%$ of the total) were considered to be directly attributable to CDAD (13). The costs for readmission alone for nosocomial CDAD per year per site was estimated to be $\$ 128,200$.

There is a suggestion that nosocomial CDAD rates are increasing in several countries, including England and Wales where a sixfold increase in rates was noted between 1990 and 1993. In the United States, rates have increased up to fivefold between the late 1980 s and the mid-1990s $(14,15)$ in at least two studies which have addressed trends over time. Rates seem to be increasing in Canada, but more data are required to corroborate whether this perception is accurate. There is an interesting dichotomy, whereby declining admission rates and shorter hospital stays have resulted in less likelihood that patients will acquire CDAD, but the increase in the burden and severity of illness and the greater likelihood of receipt of antimicrobials place this smaller group of patients at potentially greater risk of acquiring CDAD. With increasing broad spectrum antimicrobial use $(8,16)$ considered as a significant factor in the increasing rates of CDAD and with some evidence suggesting an association between bed closures and increasing nursing workload (17) with the nosocomial transmission of CDAD and vancomycin-resistant enterococci (VRE), it is interesting to speculate whether the current restructuring in the Canadian health care sector is indirectly responsible for CDAD in Canadian health care facilities. This is an area that requires further study.

Carriage rates of up to $70 \%$ have been reported in children under the age of one year, but by two years of age the 'normal' colonic flora is established and the frequency of colonization decreases to the rate of healthy adults (2). Healthy children younger than one year of age are the only population in which $C$ difficile and its toxins are frequently detected in the stool in the absence of clinical symptoms. One suggestion advanced to explain this observation is that the infant's gut lacks receptors to the toxin.

Most strains of $C$ difficile produce toxins $A$ and $B$, which are the toxins thought to be responsible for disease. Toxin A interferes with the cytoskeletons of intestinal epithelial cells and causes neutrophilic infiltration and severe mucosal damage in intestional loop assays. Both toxins A and B have been cloned and sequenced, and their binding sites to the GTP-binding protein Rho identified (18). The toxins subsequently alter the cell's cytoskeleton by disrupting F-actin microfilaments. Although toxin B is 1000 times more potent in tissue culture assays than toxin A, it has no activity in rodent intestinal loop assays. For this reason, many investigators have attributed human pseudomembranous colitis to toxin A, but recent data suggest that both toxins A and B may contribute to human disease (18). It is of interest to note that the appearance of CDAD due to toxin A-negative (by ELISA), toxin B-positive strains of $C$ difficile have been reported recently in both the United States and Canada $(19,20)$. The latter strain, reported from Winnipeg, appears to have a defective toxin A gene (21).

The gold standard for the diagnosis of $C$ difficile colitis is the tissue culture assay, with toxin neutralization demonstrated by the addition of antitoxin to $C$ difficile or Clostridium sordellii. However, this assay is not offered by most clinical laboratories. The most frequently used test are the enzyme immunoassays, the majority of which are based on the detection of toxin A. The test is highly specific, but because of a reduced sensitivity, more than a single stool should be assayed. Only $10 \%$ to $20 \%$ of patients with mild antibiotic-associated diarrhea will have a positive toxin assay for $C$ difficile, whereas up to $95 \%$ to $100 \%$ of patients with pseudomembranous colitis will have a positive assay. A high degree of clinical suspicion is required to detect ELISA toxin A-negative CDAD (19). Other testing methodologies, including cell culture or ELISAs that detect toxin A or B, are required.

In most cases of mild to moderate diarrhea, symptoms will stop when the offending antimicrobial is withdrawn. When colitis is severe, either oral metronidazole $250 \mathrm{mg}$ three times/day for 10 days or oral vancomycin $125 \mathrm{mg}$ four times/day for 10 days is usually effective. Relapses occur in about $20 \%$ to $25 \%$ of patients, and the patients usually respond to another course of therapy. A few patients experience multiple relapses, making management more difficult. The treatments for CDAD have recently been reviewed $(2,3)$, including the exciting prospect of bioprophylaxis using Saccharomyces boulardii as a lyophilized, live product to prevent recurrences (22). In addition to the appropriate stewardship of antimicrobials, perhaps these and other biological approaches will offer a solution for what is becoming the new scourge of the modern health care facility.

\section{REFERENCES}

1. Barbut F, Corthier G, Charpak Y, et al. Prevalence and pathogenicity of Clostridium difficile in hospitalized patients. A French multicenter study. Arch Intern Med 1996;156:1449-54.

2. Gerding DN, Johnson S, Peterson LR, Mulligan ME, Silva J Jr. Clostridium difficile-associated diarrhea and colitis. Infect Control Hosp Epidemiol 1995;16:459-77.

3. Fekety R. Guidelines for the diagnosis and management of Clostridium difficile-associated diarrhea and colitis. Am J Gastroenterol 1997;92:739-50.

4. Johnson S, Homann SR, Bettin KM, et al. Treatment of asymptomatic Clostridium difficile carriers (fecal excretors) with vancomycin or metronidazole. A randomized, placebo-controlled trial. Ann Intern Med 1992;117:297-302.

5. Johnson S, Clabots CR, Linn FV, Olson MM, Peterson LR, 
Gerding DN. Nosocomial Clostridium difficile colonisation and disease. Lancet 1990;336:97-100.

6. Gerding DN. Clostridium difficile-associated disease: a persistently plaguing problem. APU Newsletter 1996;14:1-6.

7. Shim JK, Johnson S, Samore MH, Bliss DZ, Gerding DN. Primary symptomless colonisation by Clostridium difficile and decreased risk of subsequent diarrhoea. Lancet 1998;351:633-6.

8. Anand A, Bashey B, Mir T, Glatt AE. Epidemiology, clinical manifestations, and outcome of Clostridium difficile-associated diarrhea. Am J Gastroenterol 1994;89:519-23.

9. Yip C, Salama S, Olde J, et al. Quinolone use was a risk factor for nosocomial Clostridium difficile-associated diarrhea. 39th Interscience Conference on Antimicrobial Agents and Chemotherapy, San Francisco, September 26 to 29, 1999. [Abst 742]

10. Hernandez F, Khorana AA, Scott JD, Feuerstein S, Forrest A, Freer JP. Incidence of Clostridium difficile colitis in patients treated with antibiotics in a community hospital setting. 9th Annual Scientific Meeting on the Society for Healthcare Epidemiology of America, San Francisco, April 18 to 20, 1999. [Abst 34]

11. Hirschhorn LR, Trnka Y, Onderdonk A, Lee ML, Platt R. Epidemiology of community-acquired Clostridium difficile-associated diarrhea. J Infect Dis 1994;169:127-33.

12. Clabots CR, Johnson S, Olson MM, Peterson LR, Gerding DN. Acquisition of Clostridium difficile by hospitalized patients: evidence for colonized new admissions as a source of infection. J Infect Dis 1992;166:561-7.

13. Miller MA, Hyland M, Ofner, M, Gourdeau M, Ishak M, the Canadian Hospital Epidemiology Committee, and the Canadian Nosocomial Infection Surveillance Program, Health Canada. Morbidity, mortality, and health-care burden of nosocomial Clostridium difficile-associated diarrhea in Canadian hospitals. 8th Annual Scientific Meeting of the Society for Healthcare Epidemiology of America. Infect Control Hosp Epidemiol 1998;19:691. [Abst 65]

14. Olson MM, Shanholtzer CJ, Lee JT Jr, Gerding DN. Ten years of prospective Clostridium difficile-associated disease surveillance and treatment at the Minneapolis VA Medical Center, 1982-1991. Infect Control Hosp Epidemiol 1994;15:371-81.

15. Manian FA, Meyer L. CDAD rates. Infect Control Hosp Epidemiol 1995;16:63-5.

16. Kelly CP, Pothoulakis C, LaMont JT. Clostridium difficile colitis. N Engl J Med 1994;330:257-62.

17. Gardam MA, McCabe N, Hurn D, Dedier H, Garcia M, Conly JM. Association of nursing workload and bed closures on nosocomial transmission of vancomycin-resistant enterococci and Clostridium difficile. 39th Interscience Conference on Antimicrobial Agents and Chemotherapy, San Francisco, September 26 to 29, 1999. [Abst 2085]

18. Pothoulakis C. Pathogenesis of Clostridium difficle-associated diarrhea. Eur J Gastroenterol Hepatology 1996;8:1041-7.

19. Depitre C, Delmee M, Avesani V, et al. Serogroup F strains of Clostridium difficile produce toxin B but not toxin A. J Med Microbiol 1993;38;434-41.

20. Embil J, Al-Barrak A, Alfa M, Dyck B, Olekson K, Nicoll D, et al. The one year experience following an outbreak of toxin $\mathrm{A}(-)$, toxin $\mathrm{B}(+)$ Clostridium difficile associated disease (CDAD) in a Canadian tertiary care center. 67 th Conjoint Meeting on Infectious Diseases in conjunction with The Canadian Infectious Disease Society Annual Meeting, Edmonton, Alberta, October 31 to November 4, 1999. Can J Infect Dis 1999;10(Suppl D):85D. [Abst SP7]

21. Alfa MJ, Lyerly D, Neville L, et al. Characterization of a toxin $\mathrm{A}(-)$, toxin $\mathrm{B}(+)$ Clostridium difficile strain that caused a diarrhea outbreak in a Canadian tertiary care hospital. 67 th Conjoint Meeting on Infectious Diseases in conjunction with The Canadian Infectious Disease Society Annual Meeting, Edmonton, Alberta, October 31 to November 4, 1999. Can J Infect Dis 1999;10(Suppl D):31D. [Abst E2]

22. McFarland LV, Surawicz CM, Greenberg RN, et al. A randomized placebo-controlled trial of Saccharomyces boulardii in combination with standard antibiotics for Clostridium difficile disease. JAMA 1994;271:1913-8. 


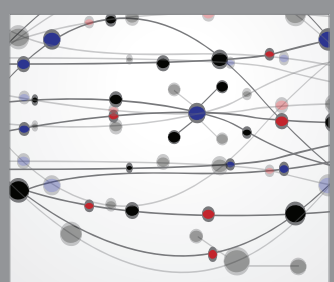

The Scientific World Journal
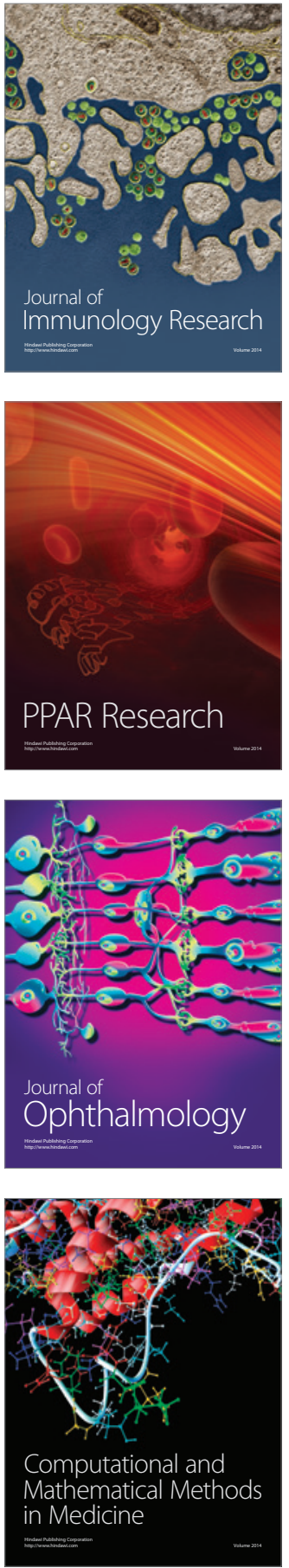

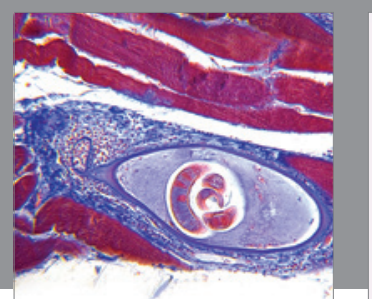

Gastroenterology Research and Practice

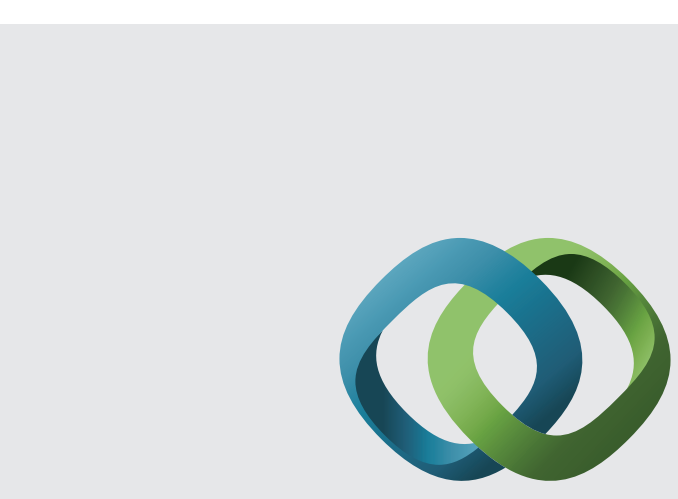

\section{Hindawi}

Submit your manuscripts at

http://www.hindawi.com
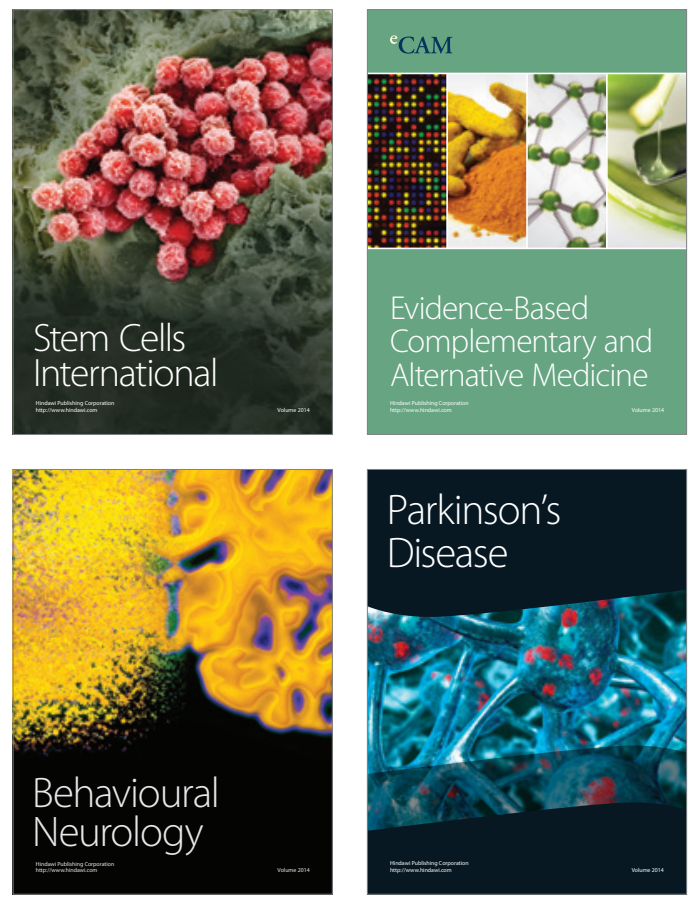
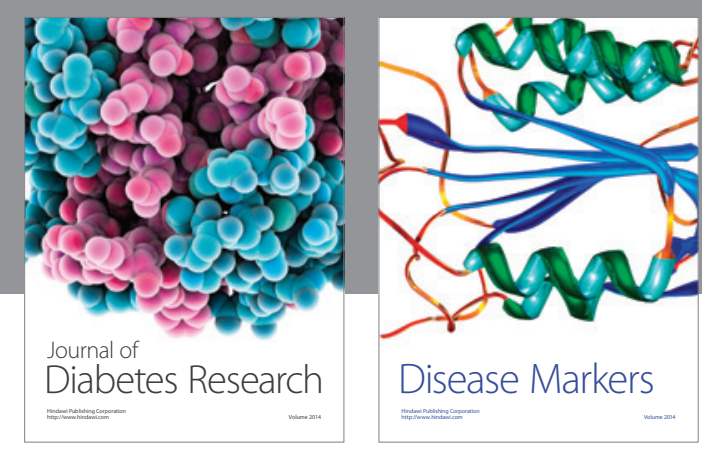

Disease Markers
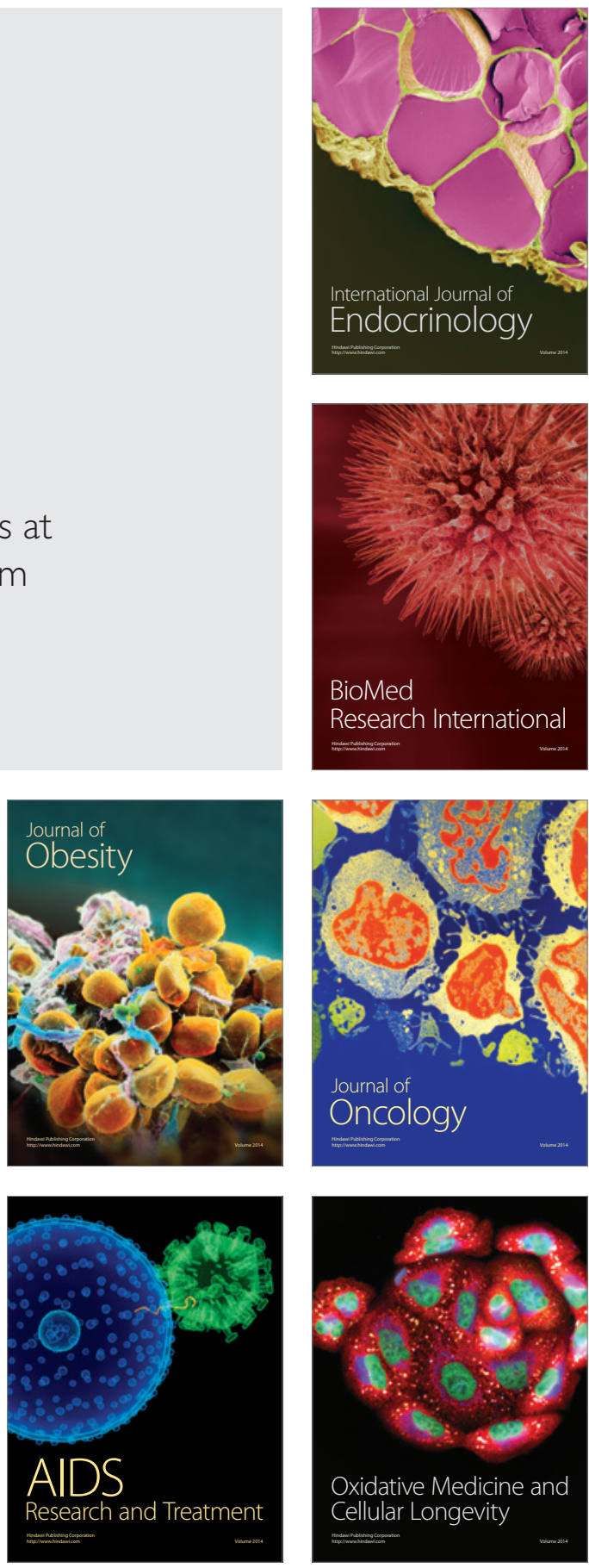